\title{
Building malaria out: improving health in the home
}

\author{
Lucy S. Tusting ${ }^{1 *}$ (D) Barbara Willey ${ }^{2}$ and Jo Lines $^{3}$ (D)
}

\begin{abstract}
Malaria prevalence has halved in endemic Africa since 2000, largely driven by the concerted international control effort. To achieve the new global targets for malaria control and elimination by 2030, and to sustain elimination once achieved, additional vector control interventions are urgently needed to supplement long-lasting insecticide-treated nets and indoor residual spraying, which both rely on effective insecticides for optimal protection. Improving housing and the built environment is a promising strategy to address this need, with an expanding body of evidence that simple modifications to reduce house entry by malaria vectors, such as closing eaves and screening doors and windows, can help protect residents from malaria. However, numerous questions remain unanswered, from basic science relating to the optimal design of house improvements through to their translation into operational use. The Malaria Journal thematic series on 'housing and malaria' collates articles that contribute to the evidence base on approaches for improving housing to reduce domestic malaria transmission.
\end{abstract}

Keywords: Malaria, Plasmodium, Anopheles, Mosquito, Disease vector, Housing, Eaves

\section{The need for supplementary malaria control interventions}

Unprecedented investment in malaria control and elimination has led to a halving of malaria prevalence in endemic Africa since 2000 [1]. Despite this progress, the disease remains intractable in many settings and a major source of morbidity and mortality worldwide. Ambitious new targets aim to reduce malaria case incidence and mortality by a further $90 \%$ globally and to eliminate malaria in 35 endemic countries during 2016-2030 [2].

Long-lasting insecticide-treated nets (LLINs) and indoor residual spraying (IRS) will certainly be needed to achieve elimination. However, to reach and stabilize the state of elimination in Africa, strategies are also needed to reduce transmission in the long term, preferably without insecticides [3].

Reliance on a small group of insecticides and antimalarial drugs has inevitably imposed massive pressure on vector and parasite populations, contributing

\footnotetext{
${ }^{*}$ Correspondence: Itusting@gmail.com

${ }^{1}$ Big Data Institute, Nuffield Department of Medicine, University of Oxford, c/o Wellcome Trust Centre for Human Genetics, Roosevelt Drive, Oxford OX3 7BN, UK

Full list of author information is available at the end of the article
}

to the widespread emergence of Anopheles resistant to pyrethroids across Africa [4] and parasites resistant to artemisinin in South East Asia [5]. Continuing effective treatment will require appropriate use of existing antimalarials as well as new combinations and new drugs. For vector control, alternative insecticide compounds are needed in the short run, but in the long run there should be less reliance on chemical-based intervention. It is well-established that malaria is both a cause and a consequence of underdevelopment, because of its intricate connections with the physical and social environment [6]. This is a challenge, but it is also an opportunity: it means that processes of economic, social and environmental development can be harnessed and used to "build malaria out".

To put this into practice, there is a need to explore opportunities to supplement existing malaria control interventions with alternative strategies that offer protection across all transmission settings and can sustainably prevent reintroduction post-elimination. Within endemic countries, it is acknowledged that tackling malaria requires the participation of all branches of government (not just the Ministry of Health) and that malaria control must be linked with plans for economic development. The 
multisectoral nature of the task has been explained by the Roll Back Malaria Partnership [7], incorporated into its implementation plans for 2016-2030 [8] and outlined within the World Health Organization's initiative for Integrated Vector Management, which is an evidence-based, adaptive and multisectoral approach to vector control [9]. The recognition that malaria needs a more integrated approach reflects the shift of perspective expressed in the Sustainable Development Goals, which emphasize the links between health and environment [10].

\section{The potential of improved housing}

Improving housing and the built environment is a promising means to support a more integrated and sustainable approach to malaria across the whole spectrum of endemicity. Anopheles mosquitoes bite during the night, and the species that transmit malaria in Africa bite mainly between 10 p.m. and 4 a.m., when most people are indoors. Therefore, structural modifications that reduce house entry by mosquitoes can help to reduce human exposure to infectious bites. Such features may include closed eaves (the gap between the top of the wall and bottom of the roof), screened doors, and windows and the presence of a ceiling [11-14]. Other mechanisms may be involved; for example, houses constructed with metal roofs may be less attractive as indoor resting places for normally endophilic mosquitoes [15]. As countries develop and disposable incomes increase, many such incremental house improvements are visibly occurring across the endemic world $[13,15,16]$.

Following decades of relative neglect as a malaria intervention, the epidemiological evidence base for improved housing is far smaller than for primary malaria interventions. Notions of "building out" malaria, first proposed by Celli [17] and Manson [18], became increasingly overlooked following the development of DDT and IRS [19]. To date, only one randomized controlled trial (RCT), conducted in The Gambia, has evaluated a house screening intervention against malaria and measured epidemiological outcomes [20]. Indeed, a recent review of housing and malaria highlighted the absence of data from many geographical regions, the paucity of intervention studies and the high risk of bias within and across studies [15].

Despite the gaps in the evidence, improved housing shows promise for reducing malaria transmission. In The Gambia, full house screening (with netting-covered doors and windows, screened ceilings and blocked eaves) reduced the prevalence of anaemia in children by $47 \%$ [20]. In a recent systematic review and meta-analysis, residents of 'modern' houses were observed to have a $47 \%$ lower odds of malaria infection and a $45-65 \%$ lower odds of clinical malaria, compared to residents of 'traditional' houses in settings across Africa, Asia and Latin
America [15]. Though the quality of the evidence was judged to be low, the direction and consistency of effects indicated that housing may be an important risk factor for malaria. This association has been observed at both extremes of the transmission spectrum, from Swaziland to Uganda [14].

\section{Where to from here?}

Key questions must be tackled if malaria control is to be supplemented with better housing [21]. These fall into four themes. First, there are basic science questions on housing interventions themselves, including what features are effective, what packages of house improvements are sufficient in different eco-epidemiological settings and their associated effectiveness. Effectiveness must be demonstrated against both entomological and epidemiological outcomes and in the context of existing interventions. Second, there are questions of safety and unintended consequences, including potentially adverse effects of interventions that reduce indoor ventilation on the risk of respiratory disease and potentially beneficial effects on nuisance biting and the transmission of other vector-borne disease. Third, the acceptability of housing interventions and their interaction with education, the use of other control measures and health-seeking behaviour must be understood. Fourth, there are critical questions on implementation, relating to cost, short- and long-term cost-effectiveness compared to conventional interventions, funding mechanisms, scale-up, sustainability and long-term maintenance and repair in both rural and urban areas.

In response to many of these questions, a promising research pipeline is emerging. For example, a second household cluster RCT is underway in The Gambia to determine whether modern housing provides incremental protection against clinical malaria over current best practice of LLINs and prompt treatment [22]. Field studies on 'eave tubes' treated with resistance-breaking actives are gaining momentum [23, 24] and other housebased malaria interventions, such as push-pull systems [25] and portable housing for mobile workers [26], continue to develop. Such research should be considered central to strengthening future malaria control and elimination efforts.

To provide a new forum for research on housing and malaria, this thematic series on 'housing and malaria' invites articles, reviews, and commentaries that contribute to the evidence base on approaches for improving housing to reduce domestic malaria transmission. The aim is to provide a platform to encourage interdisciplinary thinking; to collate evidence, old and new; and to stimulate discussion. Contributions from all disciplines are welcomed. 


\section{Abbreviations}

DDT: dichlorodiphenyltrichloroethane; IRS: indoor residual spraying; LLINs: long-lasting insecticide-treated nets; RCT: randomized controlled trial.

\section{Authors' contributions}

All authors read and approved the final manuscript.

\section{Author details}

1 Big Data Institute, Nuffield Department of Medicine, University of Oxford, c/o Wellcome Trust Centre for Human Genetics, Roosevelt Drive, Oxford OX3 7BN, UK. ${ }^{2}$ Department of Infectious Disease Epidemiology, London School of Hygiene and Tropical Medicine, Keppel Street, London WC1E 7HT, UK. ${ }^{3}$ Department of Disease Control, London School of Hygiene and Tropical Medicine, Keppel Street, London WC1E 7HT, UK.

\section{Acknowledgements}

LST is a Skills Development Fellow (No. N011570) jointly funded by the UK Medical Research Council (MRC) and the UK Department for International Development (DFID) under the MRC/DFID Concordat agreement. The authors thank the Malaria Centre at the London School of Hygiene and Tropical Medicine.

\section{Competing interests}

The authors declare that they have no competing interests.

Received: 10 May 2016 Accepted: 17 May 2016

Published online: 15 June 2016

\section{References}

1. Bhatt S, Weiss D, Cameron E, Bisanzio D, Mappin B, Dalrymple U, et al. The effect of malaria control on Plasmodium falciparum in Africa between 2000 and 2015. Nature. 2015;526:207-11.

2. WHO. Global Technical Strategy for malaria: 2016-2030. Geneva: World Health Organization; 2015.

3. Chiyaka C, Tatem A, Cohen J, Gething P, Johnston G, Laxminarayan R, et al. The stability of malaria elimination. Science. 2013;339:909-10.

4. Ranson $\mathrm{H}$, Lissenden $\mathrm{N}$. Insecticide resistance in African Anopheles mosquitoes: a worsening situation that needs urgent action to maintain malaria control. Trends Parasitol. 2016;32:187-96.

5. Ashley EA, Dhorda M, Fairhurst RM, Amaratunga C, Lim P, Suon S, et al. Spread of artemisinin resistance in Plasmodium falciparum malaria. N Engl J Med. 2014;371:411-23.

6. Tusting LS, Willey B, Lucas H, Thompson J, Toto Kafy H, Smith R, et al. Socioeconomic development as an intervention against malaria: a systematic review and meta-analysis. Lancet. 2013;382:834.

7. RBM/UNDP. Multisectoral action framework for malaria. Geneva: Roll Back Malaria Partnership/United Nations Development Programme; 2013.

8. RBM. Action and Investment to defeat malaria 2016-2030. Geneva: Roll Back Malaria Partnership; 2015.

9. WHO. Handbook on Integrated Vector Management (IVM). Geneva: World Health Organization; 2012

10. UN. Sustainable Development Goals. United Nations. 2015. http://www un.org/sustainabledevelopment/sustainable-development-goals/. Accessed 20 April 2016
11. Njie M, Dilger E, Lindsay SW, Kirby MJ. Importance of eaves to house entry by Anopheline, but not Culicine, mosquitoes. J Med Entomol. 2009:46:977-84.

12. Lwetoijera DW, Kiware SS, Mageni ZD, Dongus S, Harris C, Devine GJ, Majambere S. A need for better housing to further reduce indoor malaria transmission in areas with high bed net coverage. Parasites Vectors. 2013;6:57.

13. Liu JX, Bousema T, Zelman B, Gesase S, Hashim R, Maxwell C, et al. Is hous ing quality associated with malaria incidence among young children and mosquito vector numbers? Evidence from Korogwe, Tanzania. PLoS ONE. 2014;9:e87358.

14. Wanzirah H, Tusting LS, Arinaitwe E, Katureebe A, Maxwell K, Rek J, et al. Mind the gap: house construction and the risk of malaria in Ugandan children. PLOS ONE. 2015;10:e0117396.

15. Tusting LS, Ippolito M, Kleinschmidt I, Willey B, Gosling R, Dorsey G, et al. The evidence for improving housing to reduce malaria: a systematic review and meta-analysis. Malar J. 2015;14:209.

16. Ogoma SB, Kannady K, Sikulu M, Chaki PP, Govella NJ, Mukabana WR, et al. Window screening, ceilings and closed eaves as sustainable ways to control malaria in Dar es Salaam, Tanzania. Malar J. 2009:8:221.

17. Celli A. The new prophylaxis against malaria in Lazio. Lancet. 1900;156:1603-6.

18. Manson P. Experimental proof of the mosquito-malaria theory. BMJ. 1900;949-51.

19. Lindsay SW, Emerson PM, Charlwood JD. Reducing malaria by mosquitoproofing houses. Trends Parasite. 2002;18:510-4.

20. Kirby M, Ameh D, Bottomley C, Green C, Jawara M, Milligan P, et al. Effect of two different house screening interventions on exposure to malaria vectors and on anaemia in children in The Gambia: a randomised controlled trial. Lancet. 2009;374:998-1009.

21. RBM. Consensus statement on housing and malaria. Geneva: Roll Back Malaria Housing and Malaria Work Stream; 2015

22. Lindsay SW. Can improved housing provide additional protection against clinical malaria over current best practice? International Standard Randomised Controlled Trial Number registration; 2014. doi:10.1186/ ISRCTN02622179.

23. Andriessen R, Snetselaar J, Suer RA, Osinga AJ, Deschietere J, Lyimo IN, et al. Electrostatic coating enhances bioavailability of insecticides and breaks pyrethroid resistance in mosquitoes. Proc Natl Acad Sci USA. 2015:112:12081-6.

24. Sternberg ED, Waite $J$, Thomas MB. Evaluating the efficacy of biological and conventional insecticides with the new 'MCD bottle' bioassay. Malar J. 2014;13:499.

25. Menger DJ, Omusula P, Wouters K, Oketch C, Carreira AS, Durka M, et al. Eave screening and push-pull tactics to reduce house entry by vectors of malaria. Am J Trop Med Hyg. 2016:94:868-78.

26. Kyeba J, Madumla E, Majambere S, Okumu F. Using portable mosquitoproof housing to protect itinerant rice farmers in rural south-eastern Tanzania against vector borne infections. Am Soc Trop Med Hyg. November 2-6, 2014; New Orleans, USA (Poster 1022).

\section{Submit your next manuscript to BioMed Central and we will help you at every step:}

- We accept pre-submission inquiries

- Our selector tool helps you to find the most relevant journal

- We provide round the clock customer support

- Convenient online submission

- Thorough peer review

- Inclusion in PubMed and all major indexing services

- Maximum visibility for your research

Submit your manuscript at www.biomedcentral com/submit
Ciomed Central 